Revista Brasil. Bot., V.28, n.4, p.697-712, out.-dez. 2005

\title{
Morfoanatomia e ontogênese do fruto e semente de Byrsonima intermedia A. Juss. (Malpighiaceae)
}

\author{
LETÍCIA SILVA SOUTO ${ }^{1}$ e DENISE MARIA TROMBERT OLIVEIRA ${ }^{1,2}$
}

(recebido: 9 de dezembro de 2004; aceito: 13 de outubro de 2005)

\begin{abstract}
Morphology, anatomy, and development of Byrsonima intermedia A. Juss. (Malpighiaceae) fruit and seed). The morphology and anatomy for most of cerrado species are unknown, specially in relation to fruits and seeds. Thus, this work was carried out to analyze the morphology and anatomy of developing fruits and seeds of Byrsonima intermedia, one of the most frequent species of cerrado from São Paulo State. It was verified that the ovary is ovate, superior, tricarpellate and trilocular, with one ovule per locule; the outer epidermis is unisseriate and presents thick cuticle in the apex and thin in the base of the ovary; the mesophyll is multisseriate, parenchymatic and vascularizated; the inner epidermis is unisseriate with cells obliquelly elongated. The ovules are subcampilotropous, bitegmic, with nucellus projecting out of the micropyle; hipostasis and epistasis are observed. During the development of the pericarp, cellular divisions are restricted to the initial phase, occurring prior to the seminal differentiation. The mature fruit is fleshy, with fibrous pyrene forming three locules. The exocarp is unisseriate; the outer mesocarp is parenchymatous; in apical region of the fruit, sclereids occur surrounded by radial arranged parenchyma cells; in inner mesocarp some layers of sclereids occur, elongated in diverse ways; endocarp is multisseriate with the sclereids longitudinally elongated. The meso-endocarpic origin of the lignified regions of the pericarp is not in agreement to the classic definition of the drupoid fruits, that detaches only the wood endocarp. The seed presents reduced integuments and endosperm. The embryo axis is continuous with two cotyledons rolled spirally.
\end{abstract}

Key words - anatomy, development, fruit, morphology, "murici"

RESUMO - (Morfoanatomia e ontogênese do fruto e semente de Byrsonima intermedia A. Juss. (Malpighiaceae)). A morfologia e anatomia de muitas espécies do cerrado são desconhecidas, sendo os frutos e sementes ainda menos estudados. Assim, esse trabalho objetivou estudar morfoanatomicamente os frutos e sementes de Byrsonima intermedia, uma das espécies mais freqüentes dos cerrados de São Paulo, descrevendo-os ontogeneticamente. Verificou-se que o ovário é súpero, tricarpelar e trilocular, com um óvulo por lóculo; a epiderme externa é unisseriada, com cutícula espessa no ápice e delgada na base do órgão; o mesofilo ovariano é multisseriado, parenquimático e vascularizado; a epiderme interna é unisseriada, com células que se dividem precocemente. Os óvulos são subcampilótropos, bitegumentados, com nucelo projetado através da micrópila; hipóstase e epístase são observadas. Durante o desenvolvimento do pericarpo, as divisões celulares restringem-se à fase inicial do desenvolvimento, ocorrendo previamente à diferenciação seminal. O fruto maduro é do tipo drupóide, carnoso, com pirênio lenhoso formando três lóculos. O exocarpo é unisseriado; o mesocarpo externo é parenquimático, ocorrendo esclereídes dispersas na região apical do fruto; no mesocarpo interno ocorrem várias camadas de esclereídes alongadas em diversos sentidos; o endocarpo é multisseriado, com as esclereídes alongadas longitudinalmente. A origem meso-endocárpica dos tecidos lignificados deste pericarpo contraria a definição clássica dos frutos drupóides, que destaca apenas o endocarpo lenhoso. A semente apresenta tegumentos e endosperma reduzidos. O embrião tem eixo hipocótilo-radicular contínuo, com dois cotilédones enrolados em espiral.

Palavras-chave - anatomia, desenvolvimento, fruto, morfologia, murici

\section{Introdução}

A família Malpighiaceae é uma das dez mais bem representadas no cerrado (Mendonça et al. 1998), bioma em que há grande carência de estudos estruturais, especialmente no que se refere aos frutos e sementes.

1. Universidade Estadual Paulista, Instituto de Biociências, Departamento de Botânica, Caixa Postal 510, 18618-000 Botucatu, SP, Brasil

2._Autor para correspondência: denise@ibb.unesp.br
Essa família apresenta aproximadamente 60 gêneros e 1.200 espécies de árvores e lianas, distribuídas pelas regiões tropicais e subtropicais, especialmente no continente americano, onde ocorrem 44 gêneros e 800 espécies (Anderson 1981, Ribeiro et al. 1999).

A morfologia das flores de Malpighiaceae é bastante homogênea, mas seus frutos possuem extrema diversidade (Anderson 1979), ocorrendo frutos indeiscentes, secos e carnosos, e frutos secos deiscentes, que podem ser alados ou sem alas, glabros ou pilosos (Anderson 1990). Nas Malpighiaceae, os frutos carnosos evoluíram separada e repetidamente em diversas épocas; 
acredita-se que isso ocorreu devido ao advento de pássaros pequenos, típicos dispersores destes frutos (Anderson 1977). Tal diversidade carpológica torna bastante oportuna a realização de trabalhos como o aqui apresentado, em que foram estudados os frutos e sementes de Byrsonima intermedia A. Juss., espécie muito freqüente nos cerrados da região de Botucatu, São Paulo, Brasil.

Com relação às sementes de Malpighiaceae, nota-se que poucas espécies foram estudadas em detalhe, o que mostra a importância de trabalhos nessa área. Singh (1964) referiu o estudo da estrutura seminal de Malpighia glabra L. e Thryallis glauca (Cav.) Kuntze, enquanto Corner (1976) relatou também a de Heteropterys angustifolia Griseb. e Tristellateia australasiae A. Rich. Segundo Corner (1976), as espécies de Malpighiaceae estudadas apresentam sementes tégmicas, com exotégmen fibroso e endotégmen esclerótico, sendo que, em determinadas espécies, uma ou ambas as características tégmicas podem estar ausentes.

O gênero Byrsonima Rich. ex H.B.K. possui mais de 15 espécies (Anderson 1977), com frutos drupóides de pirênio único dividido em três lóculos (Barroso et al. 1984). Suas espécies são popularmente conhecidas como murici e apresentam rápido crescimento, flores vistosas e frutos adocicados e suculentos que atraem aves, com grande potencial para uso ornamental e para recuperação de áreas degradadas (Ribeiro et al. 1999).

Este trabalho teve por objetivo realizar o estudo morfológico e anatômico de frutos e sementes de $B$. intermedia em desenvolvimento, comparando-os com outras espécies que produzem frutos similares.

\section{Material e métodos}

Foi estudada Byrsonima intermedia A. Juss., espécie ocorrente na reserva de cerrado da Fazenda Palmeira da Serra, município de Pratânia, São Paulo, Brasil, bem como em áreas residuais de cerrado do Município de Botucatu. Ramos férteis foram herborizados e incluídos no Herbário "Irina D. Gemtchujnicov" (BOTU 24.168).

As características morfológicas dos frutos e sementes foram descritas e ilustradas a partir de amostras de 50 unidades de ovários e frutos em diversos estágios, coletadas aleatoriamente de diversos indivíduos. A nomenclatura utilizada para descrever os frutos e sementes foi baseada em Martin (1946), Corner (1976), Roth (1977) e Barroso et al. (1999). As dimensões dos frutos frescos e das sementes fixadas foram tomadas utilizando-se paquímetro digital. Para os frutos, avaliou-se também a massa da matéria fresca em balança analítica de precisão; a massa das sementes não foi tomada visto que, dada a grande dificuldade para a sua extração do interior do pirênio, foi necessário fixar o material antes de proceder à análise morfométrica.

Para o estudo anatômico, amostras dos frutos e sementes foram fixadas em FAA 50 (Johansen 1940) e armazenadas em etanol 70\%. Amostras de materiais com grande impregnação de compostos fenólicos foram fixadas diretamente em etanol 70\%, visando à remoção parcial desse conteúdo, de modo a facilitar a visualização das paredes celulares.

Para o laminário permanente, as amostras foram desidratadas em série etílica, infiltradas em metacrilato (Gerlach 1969), seccionadas em micrótomo rotatório, coradas com azul de toluidina a 0,05\%, pH 4,7 (O'Brien et al. 1964) e montadas em resina sintética.

Para o seccionamento do pirênio maduro, foi necessária a fervura em água por cerca de seis horas. Após esse período, o pirênio foi cortado em micrótomo de deslize, sendo os cortes corados com safranina e azul de astra (Kraus \& Arduin 1997) e montados em gelatina glicerinada (Dop \& Gautié 1909). Também foi realizada a maceração do pirênio, de acordo com a técnica de Franklin modificada, conforme sugerido por Kraus \& Arduin (1997).

Secções à mão livre, de material fixado, foram submetidas aos seguintes corantes e/ou reagentes: vermelho de rutênio, para identificar polissacarídeos diversos e pectinas (Jensen 1962); floroglucinol acrescido de ácido clorídrico, para evidenciar paredes lignificadas (Sass 1951); Sudan IV, para a localização de substâncias lipídicas; lugol, para a detecção de amido; cloreto férrico, acrescido de carbonato de sódio, para verificar a ocorrência de compostos fenólicos (Johansen 1940).

O laminário analisado foi fotografado em fotomicroscópio Zeiss e os desenhos foram preparados em microscópio de projeção; os aspectos gerais foram desenhados ao estereomicroscópio com câmara clara acoplada. As escalas foram produzidas de modo convencional.

\section{Resultados}

Estrutura do ovário e óvulo - Os ovários e óvulos de $B$. intermedia A. Juss. foram analisados nos botões florais e em flores em antese, exibindo estrutura similar. O ovário possui formato ovalado, é súpero (figuras 1, 2), tricarpelar e trilocular (figura 6); em cada lóculo, observa-se um único óvulo suspenso em placentação axial (figuras 6, 9). Terminais ao ovário, observam-se três estiletes inteiramente livres entre si desde a base, longos e agudos no ápice (figura 2). Na base, chama a atenção a presença do cálice pentâmero, cujas sépalas exibem amplas glândulas (figura 1). Também se destacam longos e numerosos tricomas tectores, inseridos no receptáculo entre o androceu e o gineceu, recobrindo ao menos a metade inferior do ovário 
(figura 1). Os tricomas são unicelulares e bifurcados proximalmente, sendo uma das extremidades nitidamente mais curta que a outra.

A epiderme externa do ovário é formada por camada única de células, de formato cubóide (figuras 7-9) e parede celular delgada, revestida por cutícula mais espessa na região apical do ovário, adelgaçando-se em direção à base desse órgão (figura 8). Em seu citoplasma, observa-se acúmulo de compostos fenólicos.

O mesofilo ovariano apresenta-se dividido em duas regiões; na porção externa, é formado por número variável de células parenquimáticas, cujo formato tende ao isodiamétrico e que exibem numerosas divisões celulares nos vários planos (figura 7). Muitos cristais do tipo drusa são observados nessa região, onde também ocorrem diversos idioblastos contendo compostos fenólicos. Separando as porções externa e interna, ocorrem três feixes vasculares dorsais e vários laterais (figura 6). No mesofilo ovariano interno, observam-se células parenquimáticas pequenas, com núcleo evidente e citoplasma mais denso que as externas (figuras 7, 10). Os septos são preenchidos por células parenquimáticas que variam de isodiamétricas a alongadas transversalmente (figura 11); na região axial do ovário, observam-se três feixes vasculares ventrais (figuras $6,11)$.

A epiderme interna delimita os três lóculos e é composta inicialmente por uma camada de células obliquamente alongadas, de citoplasma denso e núcleo evidente (figura 12). As células desta camada dividem-se precocemente, tanto periclinal quanto anticlinalmente (figura 12), constituindo a epiderme interna multisseriada com até três camadas de células (figura 13).

Os óvulos são alongados longitudinalmente (figuras $9,14)$ e subcampilótropos, visto que apresentam micrópila e funículo paralelos e calaza lateral (figura 14). São bitegumentados, sendo que o tegumento interno é mais longo que o externo e o nucelo projeta-se pela micrópila (figura 15).

O tegumento externo possui duas camadas de células. A camada externa apresenta células volumosas de formato retangular em corte longitudinal (figura 16), com acúmulo de compostos fenólicos em todas as suas células. A camada interna apresenta células muito delgadas, colapsadas na maioria das regiões, que se tornam nítidas quando apresentam cristais prismáticos (figura 16).

$\mathrm{O}$ tegumento interno possui cerca de quatro camadas de células de paredes delgadas e núcleo evidente (figura 16). A epiderme externa constitui-se de uma camada de células de formato quadrangular em vista longitudinal; em sua parede periclinal externa, observa-se uma cutícula delgada que indica o limite entre o tegumento externo e o tegumento interno (figura 16). As células do mesofilo possuem formatos cubóides a ligeiramente alongados. A epiderme interna é unisseriada e suas células são semelhantes às da epiderme externa (figura 16).

No funículo, observa-se um feixe vascular irrigando o óvulo, que é crassinucelado (figura 14). O nucelo é constituído por células de formatos variáveis e núcleos evidentes (figura 16). A região adjacente à calaza apresenta hipóstase distinta (figura 14), constituída por um tecido com impregnação de compostos fenólicos. Também se encontra diferenciada a epístase, na extremidade micropilar do nucelo, composta por células pequenas (figura 15) e fenólicas.

Fruto em desenvolvimento - Durante o desenvolvimento, observa-se aumento no tamanho do fruto, que mantém o aspecto externo similar ao do ovário. $\mathrm{O}$ cálice é persistente. Nesta fase, prevalece o alongamento celular, especialmente no mesocarpo e endocarpo, embora divisões ainda possam ocorrer mais esporadicamente no mesocarpo externo.

O exocarpo continua unisseriado (figuras 17, 19), com o conteúdo fenólico evidente. A parede periclinal externa apresenta cutícula de espessura variável, espessa no ápice e pouco distinta na base (figura 17).

No mesocarpo jovem, distinguem-se duas regiões (figuras 17-18, 29-31). No mesocarpo externo, destaca-se a camada subexocárpica, composta por células bem justapostas, tendendo a ligeiramente paliçádicas na porção basal do fruto, de paredes delgadas e com grande acúmulo de compostos fenólicos; o restante do mesocarpo externo é também parenquimático, composto por células mais ou menos isodiamétricas, onde o acúmulo de compostos fenólicos forma distintas redes de idioblastos (figuras 18, 20). Nesta região, algumas divisões celulares ainda podem ser observadas (figura 19).

Durante o desenvolvimento, as células do mesocarpo externo aumentam de tamanho e as divisões celulares cessam. Nos dois terços distais do fruto jovem, ocorre a diferenciação de esclereídes, agrupadas em conjuntos de duas a quatro células. Inicialmente, as células parenquimáticas circunvizinhas apresentam tamanho inferior ao das esclereídes; com o desenvolvimento do fruto, essas células tornam-se similares às esclereídes em relação ao tamanho (figura 30). No terço proximal do fruto, não ocorre diferenciação de esclereídes.

O mesocarpo interno inicia-se na região onde os feixes dorsais e laterais estão imersos e é composto por várias camadas de células pequenas, de conteúdo mais 
denso que as externas e núcleo evidente (figuras 20, 21); nesta fase, tais células alongam-se em sentidos variáveis (figura 31), ocorrendo a lignificação de algumas poucas células (figura 32). Ao final do desenvolvimento, o número de camadas de células tornase variável, devido à ampliação variável dessas camadas, o que produz o contorno irregular do mesocarpo interno (figuras 17, 29).

Nos septos, não se distingue o mesocarpo externo e as células do mesocarpo interno alongam-se mais freqüientemente no sentido transversal (figuras 22, 23, 33). Na região axial do fruto (região ventral), observam-se os três feixes ventrais, muito próximos na base do fruto (figura 22), distanciando-se à medida que se aproxima do ápice (figura 23). Observam-se idioblastos fenólicos delimitando os feixes ventrais em conjunto na base (figura 22) ou individualmente no ápice (figura 23); também podem ser verificados idioblastos fenólicos formando pequenas faixas ao longo dos septos (figuras 22, 23).

No início desta fase, o endocarpo é multisseriado, com três a quatro camadas de células que se alongam longitudinalmente (figuras 20,21).

A semente aumenta muito de tamanho, até atingir o tamanho e a forma globosa característica da semente madura, embora mantenha o aspecto similar ao do óvulo (figuras 24, 34). As maiores modificações só são iniciadas quando o fruto já atingiu o seu tamanho final. A estrutura mantém-se bitegumentada e os tegumentos muito similares aos do óvulo (figuras 25,26 ), podendo-se observar eventuais estômatos na exotesta (figura 26). Nota-se, ainda, que o endotégmen encontra-se constituído por camada unisseriada de células de citoplasma significativamente mais denso que das demais regiões (figura 26). Ao final deste período, os tegumentos começam a se reduzir por compressão, colapsando-se em algumas regiões.

O nucelo persiste abundantemente até esta fase (figuras 24, 25, 34), delimitando-se nitidamente a hipóstase (figuras 24, 34, 35) e a epístase (figuras 24, 27). O principal indício de que a fecundação aconteceu é a formação do endosperma nuclear (figura 28), já que o embrião tem desenvolvimento muito lento, ocorrendo todo o processo de embriogênese paralelo à maturação pericárpica.

Fruto maduro - $\mathrm{O}$ fruto maduro tem formato ligeiramente ovalado (figura 4) e coloração amarela. Sua consistência é carnosa superficialmente, formando um pirênio muito lenhoso com três lóculos bem delimitados. O cálice é persistente, assim como as glândulas calicinais (figura 3). Verificam-se, ainda, os tricomas tectores receptaculares, agora comprimidos entre a base do fruto e o cálice (figura 3). Os três estiletes também persistem no fruto (figuras 4, 5).

O fruto apresenta dimensões de 7,70-11,00 $\times$ 7,77-10,78 cm, com massa da matéria fresca de 0,29-0,71 g. Em relação ao número de sementes, encontram-se frutos sem nenhuma semente madura, com uma, duas ou três sementes, sendo esta última a condição mais freqüente.

O exocarpo conserva-se unisseriado, formado por células de contorno quadrangular a retangular em corte

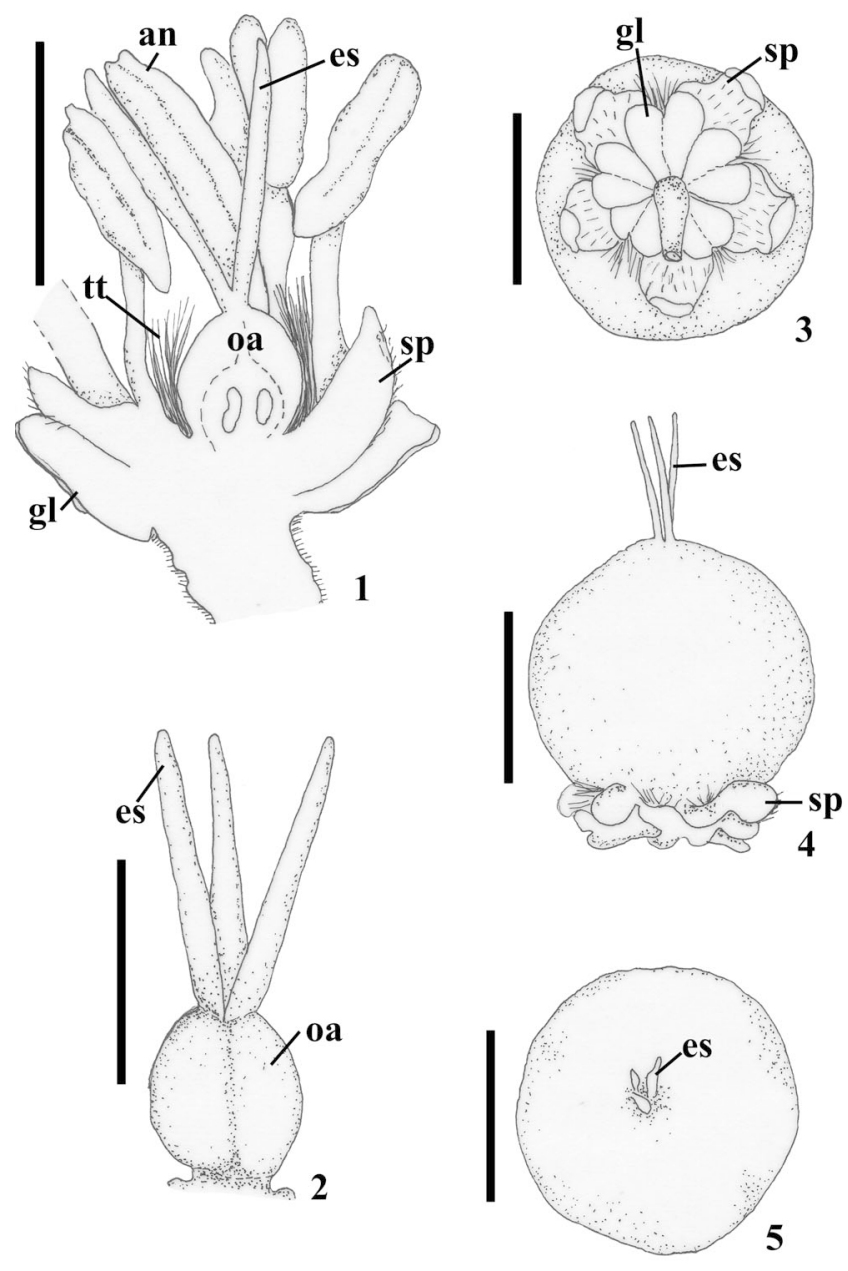

Figuras 1-5. Byrsonima intermedia. 1. Flor em corte longitudinal, após remoção das pétalas. 2. Aspecto do ovário isolado. 3-5. Aspectos do fruto maduro em vista basal, lateral e apical respectivamente. (an = antera; es = estilete; $\mathrm{gl}=$ glândula calicinal; oa = ovário $\mathrm{sp}=$ sépala $; \mathrm{tt}=$ tricoma tector). Barras = $3 \mathrm{~mm}$ (1), $2 \mathrm{~mm}$ (2), $5 \mathrm{~mm}$ (3-5).

Figures 1-5. Byrsonima intermedia. 1. Flower in longitudinal section, after petals removal. 2. Aspect of the isolated ovary. 3-5. Aspects of the mature fruit in basal, lateral, and apical view, respectively. $(\mathrm{an}=$ anther; es = style; $\mathrm{gl}=$ calyx gland; $\mathrm{oa}=$ ovary; $\mathrm{sp}=$ sepal; $\mathrm{tt}=$ non-glandular trichome). Bars $=3 \mathrm{~mm}(1), 2 \mathrm{~mm}(2), 5 \mathrm{~mm}(3-5)$. 
transversal (figura 38), que acumulam compostos fenólicos; estômatos de pequeno tamanho são observados eventualmente (figura 37). Apicalmente, as paredes periclinais externas são revestidas por cutícula espessa (figura 38), adelgaçando-se em direção à base.

O mesocarpo externo é composto por parênquima de células volumosas, variando de isodiamétricas a algo alongadas (figuras 36-40), com grande acúmulo de compostos lipídicos e fenólicos. Entre as células das camadas periféricas, formam-se nítidos espaços intercelulares esquizógenos (figura 38).

A região apical do fruto apresenta grupos de esclereídes circundados pelas células parenquimáticas em um arranjo radial (figura 40). Na região basal, não se verificou a diferenciação das esclereídes, não havendo, portanto, os arranjos radiais de células parenquimáticas. Cristais do tipo drusa são observados dispersos pelo mesocarpo externo.

Nas camadas mais internas do mesocarpo externo, as células parenquimáticas apresentam menor tamanho e variam de isodiamétricas a levemente alongadas, tangencialmente ao mesocarpo interno (figura 36). Entremeados nesta região, observam-se feixes vasculares colaterais de pequeno tamanho (figura 39).

No mesocarpo interno, as células alongadas em diversos sentidos formam numerosas camadas de esclereídes (figuras 43, 44); observam-se braquiesclereídes e esclereídes mais alongadas, de formatos variáveis.

O endocarpo é multisseriado, formado por várias camadas de esclereídes alongadas no sentido longitudinal do fruto (figura 42). Nos septos e na região axial, a lignificação é completa, abrangendo todo o mesocarpo interno e o endocarpo (figuras 41,42). Junto aos feixes ventrais, o mesocarpo interno mostra esclereídes verticais (figura 41), que também aparecem em blocos diapostos aleatoriamente, entre células oblíquas e horizontais. No endocarpo, a disposição das esclereídes é sempre vertical (figuras 41, 42). Deve-se destacar a presença de conteúdo fenólico preenchendo o lúmen da maior parte das esclereídes mesocárpicas (figuras 43, 44) e endocárpicas.

Durante esta fase, o nucelo é consumido na diferenciação do embrião, o qual ocupa quase toda a amêndoa. As sementes maduras são enegrecidas e obovadas, apresentando lobo radicular discreto (figura 45), sobre o qual encontra-se a micrópila (figura 46); o hilo é diminuto e observa-se, próxima a ele, uma área mais pigmentada que é a hipóstase (figuras 45,46 ). As sementes maduras medem $0,22-0,43 \times 0,21-0,35 \times$ $0,13-0,24 \mathrm{~cm}$.
Os tegumentos encontram-se muito reduzidos. Observam-se apenas resíduos de células colapsadas, com impregnações fenólicas compondo a testa, e as paredes lignificadas de uma camada unisseriada que corresponde ao endotégmen (figura 48).

Com relação ao endosperma, observa-se somente um resíduo com cerca de duas camadas de células, de formatos variáveis e citoplasma repleto de gotículas lipídicas (figura 48).

O embrião apresenta eixo hipocótilo-radicular curto (figura 47), que continua com dois cotilédones adjacentes e enrolados em espiral sobre si (figuras 47, 49). A protoderme do cotilédone é formada por células retangulares em corte longitudinal (figura 50), recobertas externamente por cutícula delgada, armazenando gotículas lipídicas e compostos fenólicos. O meristema fundamental exibe células cubóides ou isodiamétricas, maiores que as da protoderme (figura 50), que também acumulam numerosas gotículas lipídicas e substâncias fenólicas; as células mais próximas à protoderme apresentam predomínio de compostos fenólicos, enquanto nas células próximas ao centro do cotilédone predominam gotículas lipídicas. Em cada cotilédone, observa-se um cordão procambial (figuras 47, 49, 50), que se origina no eixo embrionário e percorre toda a extensão cotiledonar (figura 47).

No eixo embrionário, verifica-se a distribuição típica dos tecidos meristemáticos primários e pode-se observar nítido primórdio de coifa (figura 51).

\section{Discussão}

No estudo ontogenético de frutos carnosos, especialmente dos drupóides, é comum a divisão em períodos de crescimento (Lilleland 1930, 1932, 1933, Tukey \& Young 1939, Nitsch 1953). Esses autores reconheceram os seguintes períodos de desenvolvimento: I - ocorre rápido aumento no tamanho do fruto e tegumentos seminais; II - o embrião diferencia-se, embora a velocidade de crescimento do fruto diminua sensivelmente; III - há paralisação do desenvolvimento do embrião e retomada de um ativo alongamento do fruto. Em B. intermedia A. Juss., observou-se que o desenvolvimento dos frutos não segue esse padrão. Nesta espécie, o fruto apresenta divisões celulares no mesocarpo e endocarpo, seguido de alongamento celular, enquanto a semente jovem aumenta de tamanho, mas sem diferenciar os tegumentos ou o embrião, que se encontra nos primeiros estágios de desenvolvimento. Quando o pericarpo está em fase final de maturação, o embrião continua seu desenvolvimento rapidamente, não havendo 
retomada de crescimento do fruto.

Segundo a classificação de Barroso et al. (1999), os frutos de $B$. intermedia são considerados do tipo drupóide, subtipo nuculânio oligospermo. Os frutos drupóides têm como principal característica o endocarpo lignificado, constituindo o pirênio (endocarpo lenhoso envolvendo completamente a semente). Com base no estudo ontogenético aqui realizado e adotando-se a definição de camadas pericárpicas preconizada por Roth (1977), o tecido que se esclerifica em $B$. intermedia é composto pelo endocarpo e por uma ampla camada de células mesocárpicas internas. Esse tipo de estrutura foge à definição clássica dos frutos drupóides. Recentes estudos têm registrado que outras espécies produtoras de drupas ou frutos drupóides também não se enquadram precisamente na definição clássica encontrada na literatura. Nakamura (2003) relatou que o pirênio de três espécies de Erythroxylum P. Browne é formado por uma camada de tecido esclerificado que é derivado do meristema subadaxial, mesocárpica portanto; a autora destaca que, em Erythroxylum cuneifolium (Mart.) O.E. Schulz, o mesocarpo médio também se esclerifica. Em Styrax camporum Pohl., Julio (2003) observou o endocarpo lignificado e delgado, com consistência papirácea, sendo que a região lignificada e mais rígida tem origem tegumentar. É importante, portanto, reverse a definição desse tipo de fruto, ampliando-se o conceito de pirênio para abranger camadas pericárpicas internas lignificadas, mesocárpicas e/ou endocárpicas. Contudo, não havendo classificação mais adequada, os frutos de $B$. intermedia podem ser classificados como drupóides.

Byrsonima intermedia apresenta os tricomas característicos da família Malpighiaceae no receptáculo, sendo que estes permanecem associados ao fruto, entre o pericarpo e o cálice persistente característico das Malpighiaceae. Também deve ser destacado que, no ovário, a cutícula se torna mais espessa à medida que se distancia da base desse órgão; tal variação é mantida no fruto até sua maturidade. Levando-se em consideração que tricomas tectores e cutícula espessa estão relacionados à proteção contra perda de água e contra a predação, pode-se constatar que $B$. intermedia apresenta maior investimento no espessamento da cutícula na região em que o ovário e, posteriormente, o pericarpo, ficam expostos ao ambiente, sem estarem recobertos e protegidos pelos tricomas receptaculares.

Vale destacar a grande constância de caracteres ovarianos nas espécies de Malpighiaceae. Corner (1976) registrou que Heteropterys Kunth, gênero samaróide da família, apresenta ovário trilocular com um óvulo por lóculo e placentação axial. Também para Janusia guaranitica (A. St.-Hil.) A. Juss., Lorenzo (1981) descreveu caracteres similares, embora destacando que os três carpelos são unidos na base e livres no ápice. Apesar de se observarem variações no formato do ovário, a morfologia geral descrita para os gêneros anteriormente citados reflete o padrão encontrado em $B$. intermedia.

Com relação ao óvulo e à semente, algumas características descritas por Corner (1976) para a família também são observadas para $B$. intermedia, como os óvulos solitários em cada lóculo, suspensos, bitegumentados e crassinucelados. Além disso, ainda corroboram os dados de Corner (1976) a ocorrência de nucelo projetado através da micrópila e as características gerais dos tegumentos, sendo a semente endotégmica.

Uma das características que chamam a atenção nas sementes de $B$. intermedia é a evidente diferenciação da hipóstase e da epístase. Corner (1976) e Werker (1997) registram que a hipóstase é característica típica de algumas famílias de monocotiledôneas como Amaryllidaceae, Cyperaceae, Liliaceae e Zingiberaceae e de cerca de 81 famílias de dicotiledôneas, estas listadas por Von Teichman \& Van Wyk (1991). O registro da hipóstase para Malpighiaceae não havia sido feito por nenhum desses autores.

De acordo com Von Teichman \& Van Wyk (1991), após analisarem dados próprios e disponíveis na literatura para as 81 famílias de dicotiledôneas cujas sementes

Figures 6-13. Ovary of floral buds and anthesis flowers of Byrsonima intermedia. Transverse sections (6, 7, 10-12). Longitudinal sections $(8,9,13) .6$. General view, showing the three loculi with one ovule each $(*=$ dorsal bundle; arrowhead $=$ ventral bundle). 7 . Detail of the ovarian wall, near the apical region, showing cellular divisions $(*) .8$. General aspect, evidencing thin cuticle in the base (arrowhead), thickening in direction to apex (double arrowhead). 9. Detail of the placenta region. 10-11. Details of the dorsal and ventral region, respectively. 12. Detail of the inner epidermis of the young ovary, detaching the first periclinal divisions (arrowhead). 13. Detail of the inner epidermis of the ovary, after the periclinal divisions. ( $\mathrm{ei}=$ inner epidermis; $\mathrm{es}=$ style; $\mathrm{fd}=$ dorsal bundle; $\mathrm{fu}=$ funicle; $\mathrm{fv}=$ ventral bundle; lo = locule; $\mathrm{ml}=\mathrm{inner}$ ovarian mesophyll; $\mathrm{ms}=$ outer ovarian mesophyll; ov = ovule; po = ovarian wall). Bars $=200 \mu \mathrm{m}(6,8), 50 \mu \mathrm{m}(7,11), 100 \mu \mathrm{m}(9), 25 \mu \mathrm{m}$ $(10,13), 10 \mu \mathrm{m}(12)$. 

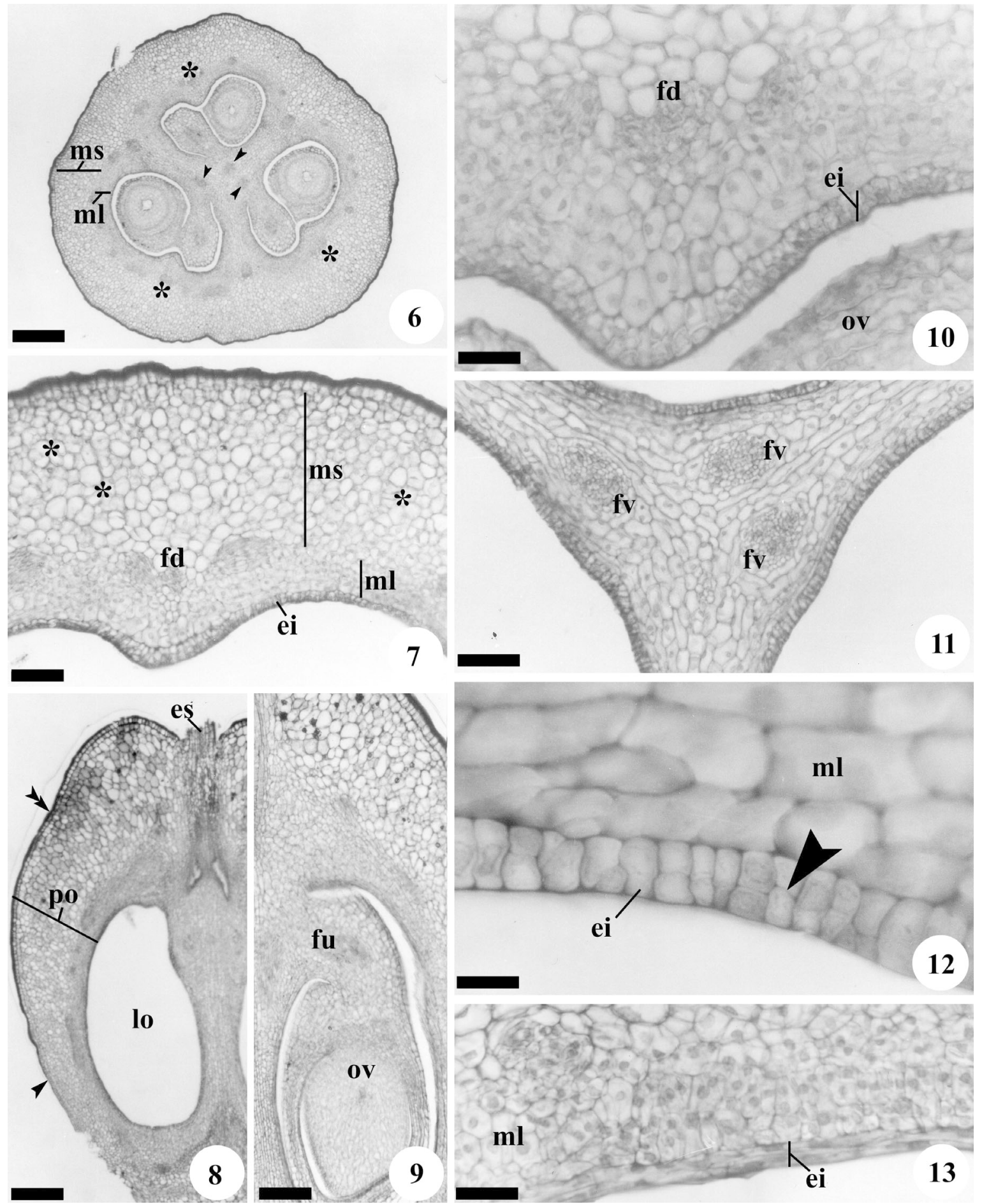

12

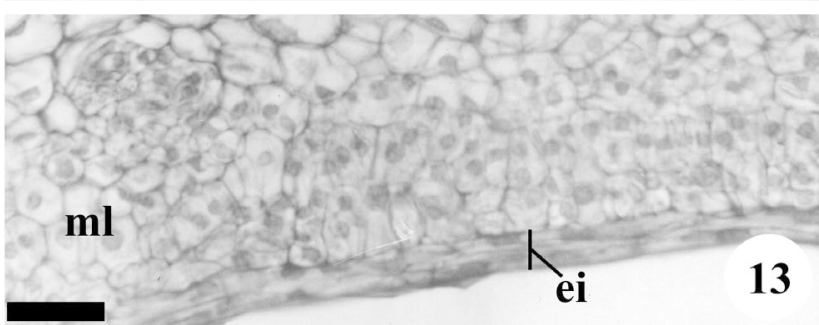

Figuras 6-13. Ovários de botões florais e flores em antese de Byrsonima intermedia. Secções transversais (6, 7, 10-12). Secções longitudinais $(8,9,13) .6$. Vista geral, mostrando os três lóculos contendo um óvulo cada $(*=$ feixe dorsal; ponta de seta $=$ feixe ventral). 7. Detalhe da parede, próximo ao ápice do ovário, mostrando divisões celulares (*). 8. Aspecto geral, evidenciando a cutícula delgada na base (ponta de seta), espessando em direção ao ápice (dupla ponta de seta). 9. Detalhe da região de placentação. 10-11. Detalhes da região dorsal e ventral, respectivamente. 12. Detalhe da epiderme interna do ovário mais jovem, destacando as primeiras divisões periclinais (ponta de seta). 13. Detalhe da epiderme interna do ovário, após as divisões periclinais. (ei = epiderme interna; $\mathrm{es}=$ estilete; $\mathrm{fd}=$ feixe dorsal; $\mathrm{fu}=$ funículo; $\mathrm{fv}=$ feixe ventral; lo = lóculo; $\mathrm{ml}=$ mesofilo ovariano interno; $\mathrm{ms}=$ mesofilo ovariano externo; ov = óvulo; $\mathrm{po}=$ parede ovariana). Barras $=200 \mu \mathrm{m}(6,8), 50 \mu \mathrm{m}(7,11)$, $100 \mu \mathrm{m}(9), 25 \mu \mathrm{m}(10,13), 10 \mu \mathrm{m}(12)$. 


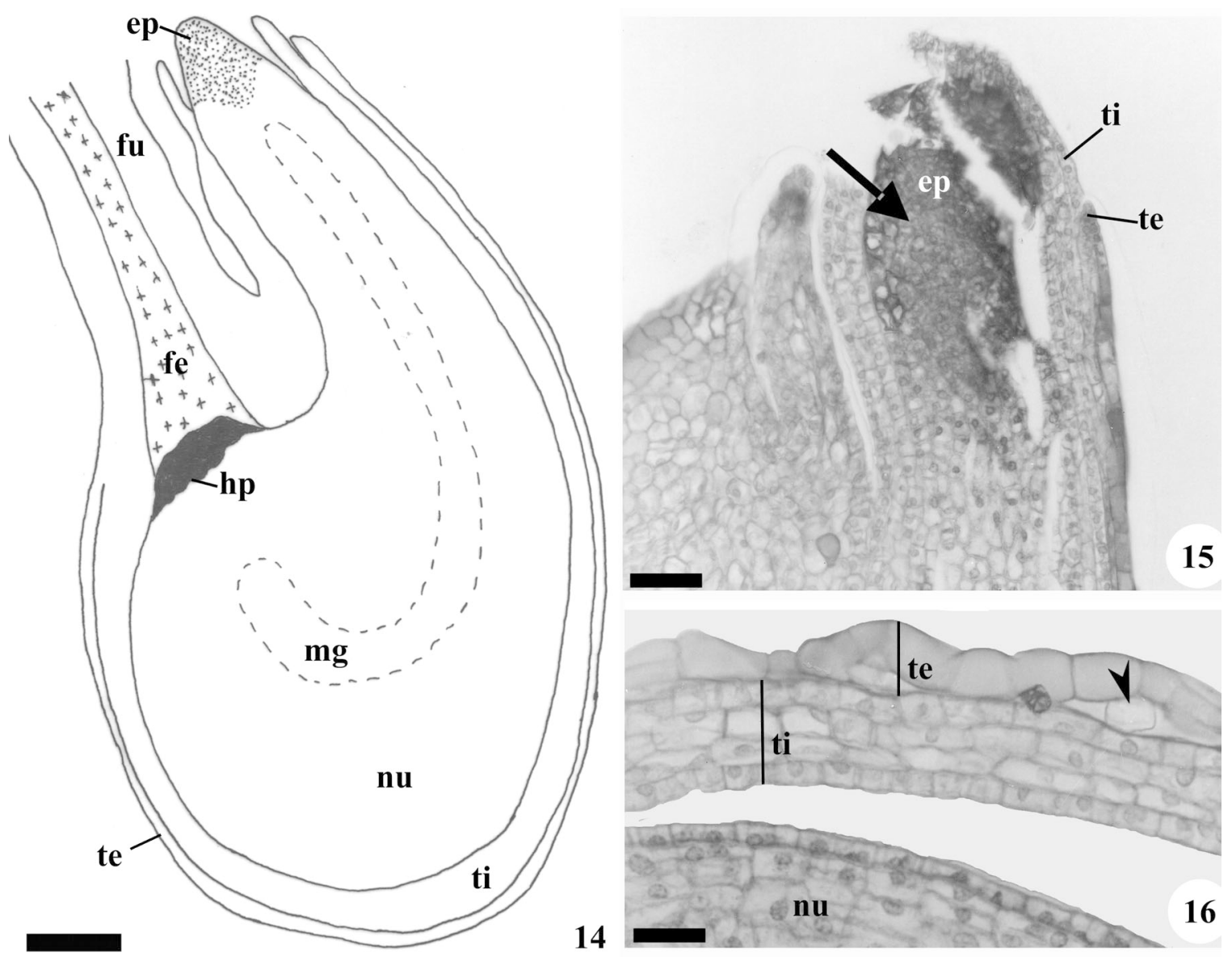

Figuras 14-16. Óvulo de Byrsonima intermedia. Secções longitudinais. 14. Aspecto geral do óvulo, mostrando o saco embrionário (megagametofito). 15. Detalhe da região micropilar, destacando os tegumentos e a projeção nucelar constituindo a epístase; observar substâncias fenólicas nas células da epístase (seta). 16. Detalhe dos tegumentos (ponta de seta: cristal prismático). $(\mathrm{ep}=$ epístase $; \mathrm{fe}=$ feixe vascular; fu = funículo; $\mathrm{hp}=$ hipóstase; $\mathrm{mg}=$ megagametofito; nu = nucelo; te $=$ tegumento externo; $\mathrm{ti}=$ tegumento interno). Barras $=100 \mu \mathrm{m}(14), 50 \mu \mathrm{m}(15), 25 \mu \mathrm{m}(16)$.

Figures 14-16. Ovule of Byrsonima intermedia. Longitudinal sections. 14. General aspect of ovule, showing the megagametophyte. 15. Detail of the micropylar region, detaching the integuments and the nucellar projection constituting the epistasis; note the cells of the epistasis with phenolic compounds (arrow). 16. Detail of the integuments (arrowhead: prismatic crystal). $(\mathrm{ep}=$ epistasis; $\mathrm{fe}=$ vascular bundle $; \mathrm{fu}=$ funicle $; \mathrm{hp}=$ hipostasis; $\mathrm{mg}=$ megagametophyte; $\mathrm{nu}=$ nucellus; te $=$ outer integument; $\mathrm{ti}=$ inner integument). Bars = $100 \mu \mathrm{m}$ (14), $50 \mu \mathrm{m}(15), 25 \mu \mathrm{m}(16)$.

Figures 17-23. Young fruit of Byrsonima intermedia. Longitudinal sections (17, 19, 21). Transverse sections (18, 20, 22, 23). 17. General view of the fruit after phenolic compounds removal, showing the young seeds with similar aspect to the ovule; to note thin cuticle in the base of fruit (arrowhead) and thick in the apex (double arrowhead). 18. Aspect of the pericarp apical region, detaching nets of mesocarpic phenolic idioblasts (arrowheads). 19. Detail of exocarp and outer mesocarp next to the apex of the fruit, evidencing the subexocarpic layer $(*)$, the cellular divisions (arrowheads) and the cells with phenolic compounds (arrow). 20-21. Details of the outer and inner mesocarp, and multisseriate endocarp. 22. Aspect of septum in the basal region of fruit, showing the ventral bundles joined and accompanied by phenolic idioblasts (arrow). 23. Aspect of septum in the apical region of fruit, evidencing the isolate ventral bundles; between them, note phenolic idioblasts (arrow). ( cs = seminal cavity; en = endocarp; ex = exocarp; $\mathrm{fe}=$ vascular bundle; $\mathrm{fv}=$ ventral bundle; $\mathrm{me}=$ outer mesocarp; $\mathrm{mi}=$ inner mesocarp; pe = pericarp; se = septum; sm = seed). Bars $=200 \mu \mathrm{m}(17), 100 \mu \mathrm{m}(18), 50 \mu \mathrm{m}(19,20,22,23), 25 \mu \mathrm{m}(21)$. 

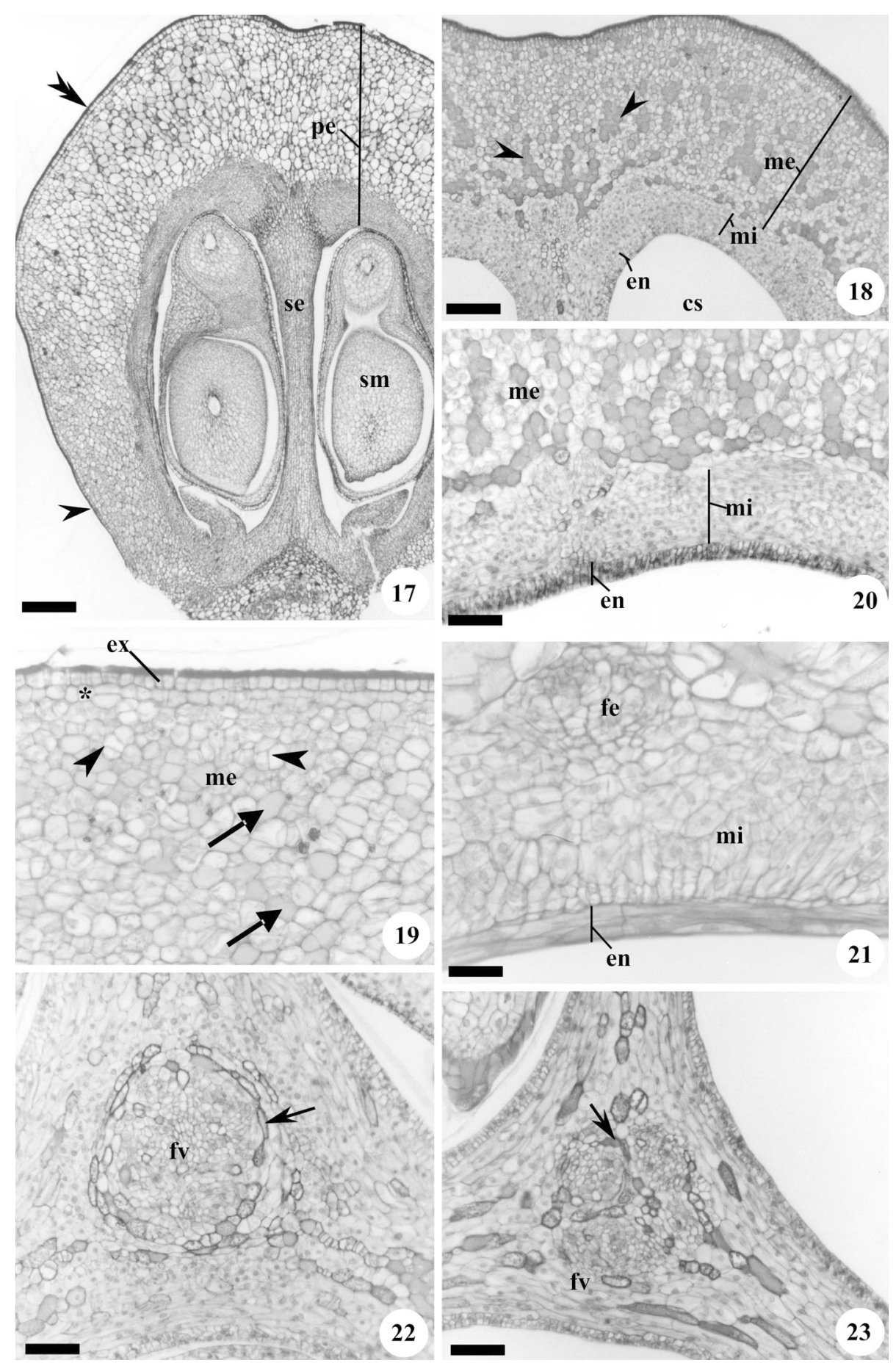

Figuras 17-23. Fruto jovem de Byrsonima intermedia. Secções longitudinais (17, 19, 21). Secções transversais (18, 20, 22, 23). 17. Vista geral do fruto após remoção dos compostos fenólicos, mostrando as sementes jovens com aspecto similar aos óvulos; notar cutícula delgada na base do fruto (ponta de seta) e espessa no ápice (dupla ponta de seta). 18. Aspecto da região apical do pericarpo, destacando redes de idioblastos fenólicos mesocárpicos (pontas de setas). 19. Detalhe do exocarpo e mesocarpo externo próximo ao ápice do fruto, evidenciando divisões celulares (pontas de setas) e a camada subexocárpica $(*)$, além de células com conteúdo fenólico (seta). 20-21. Detalhes do mesocarpo externo, interno e do endocarpo multisseriado. 22. Aspecto do septo na região basal do fruto, mostrando os feixes ventrais próximos e acompanhados por idioblastos fenólicos (seta). 23. Aspecto do septo na região apical do fruto, evidenciando os feixes ventrais separados; entre eles, notar idioblastos fenólicos (seta). (cs = cavidade seminal; en = endocarpo; ex = exocarpo; fe = feixe vascular; fv = feixe ventral; $\mathrm{me}=$ mesocarpo externo; $\mathrm{mi}=$ mesocarpo interno; $\mathrm{pe}=$ pericarpo; $\mathrm{se}=$ septo; $\mathrm{sm}=$ semente $).$ Barras $=200 \mu \mathrm{m}(17), 100 \mu \mathrm{m}(18)$, $50 \mu \mathrm{m}(19,20,22,23), 25 \mu \mathrm{m}(21)$. 


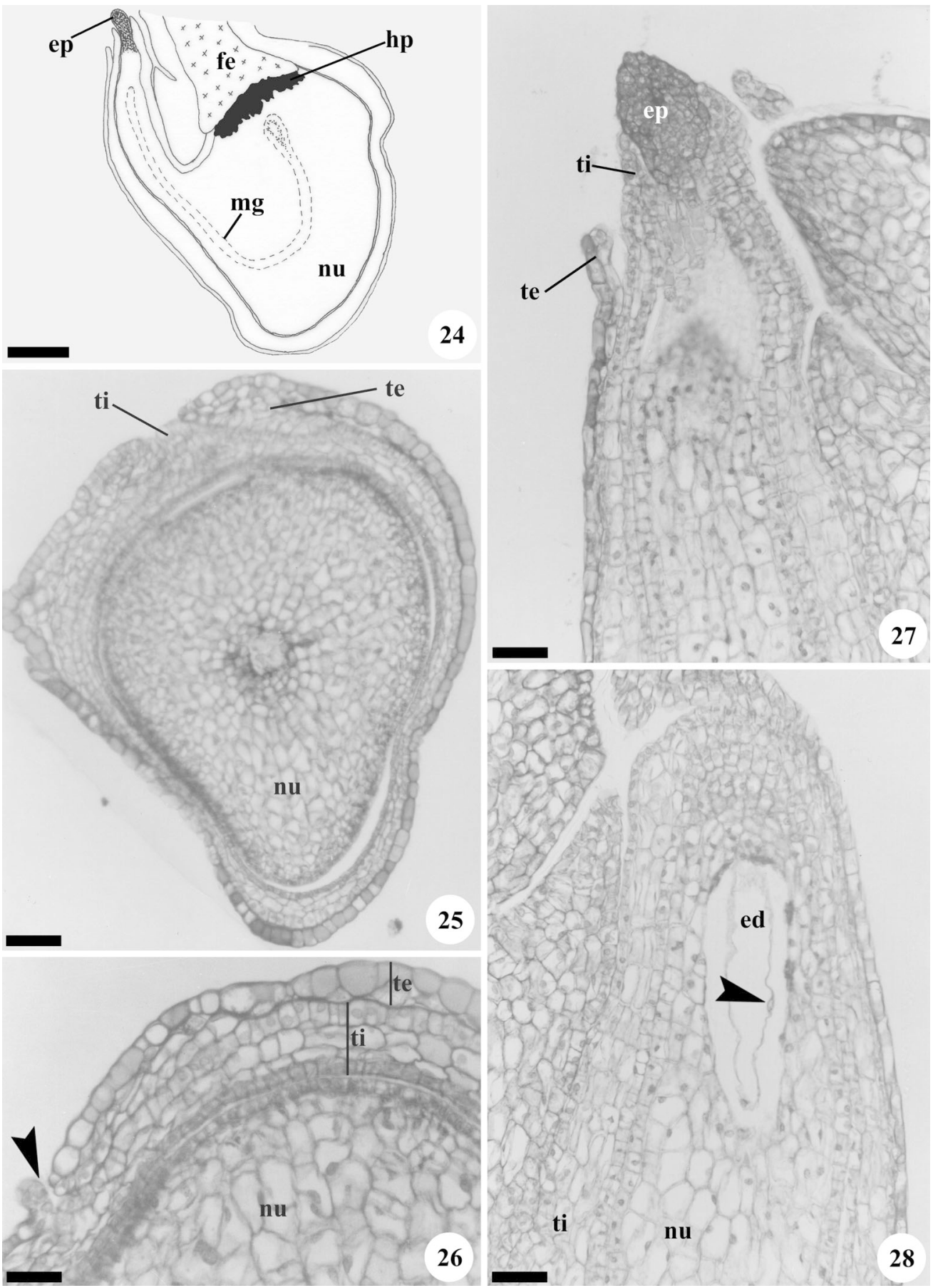

Figuras 24-28. Sementes em desenvolvimento de Byrsonima intermedia. Secções longitudinais (24, 26-28). Secção transversal (25). 24. Aspecto geral; notar a grande semelhança com o óvulo. 25. Detalhe do tegumento e nucelo, próximos à região micropilar. 26. Detalhe do tegumento evidenciando um estômato (ponta de seta). 27. Detalhe da região micropilar. 28. Detalhe da semente com endosperma nuclear (ponta de seta: núcleos livres). (ed = endosperma; ep = epístase; fe = feixe vascular; $\mathrm{hp}=$ hipóstase $; \mathrm{mg}=$ megagametofito; $\mathrm{nu}=$ nucelo; te $=$ tegumento externo; $\mathrm{ti}=$ tegumento interno). Barras $=250 \mu \mathrm{m}$ (24), $50 \mu \mathrm{m}(25,27,28), 25 \mu \mathrm{m}(26)$.

Figures 24-28. Developing seeds of Byrsonima intermedia. Longitudinal sections (24, 26-28). Transverse sections (25). 24. General aspect; note the great similarity with the ovule. 25. Detail of the integument and nucellus, near to the micropylar region. 26. Detail of the integument, evidencing one stoma (arrowhead). 27. Detail of the micropylar region. 28. Detail of the seed with nuclear endosperm (arrowhead: free nuclei). $(\mathrm{ed}=$ endosperm; $\mathrm{ep}=$ epistasis; $\mathrm{fe}=$ vascular bundle; $\mathrm{hp}=$ hipostasis; $\mathrm{mg}=$ megagametophyte; $\mathrm{nu}=$ nucellus; te $=$ outer integument; $\mathrm{ti}=$ inner integument $).$ Bars $=250 \mu \mathrm{m}(24), 50 \mu \mathrm{m}(25,27,28)$, $25 \mu \mathrm{m}(26)$. 


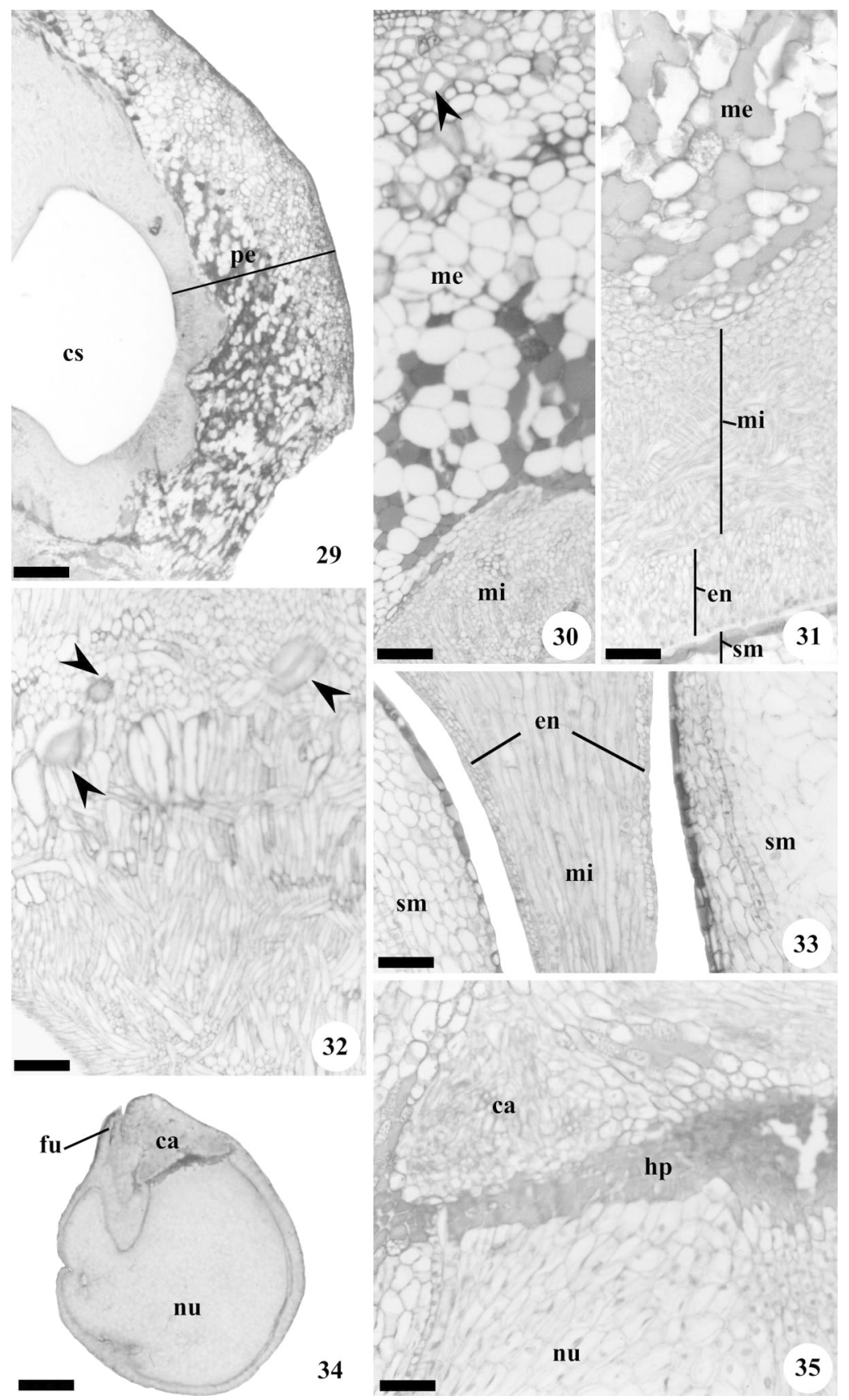

Figuras 29-35. Fruto de Byrsonima intermedia no final da fase de alongamento celular. Secções longitudinais $(29,30,32,34,35)$. Secções transversais $(31,33)$. 29. Aspecto geral do pericarpo. 30. Detalhe do pericarpo (ponta de seta = esclereíde). 31. Detalhe da região interna do pericarpo, destacando a estrutura do mesocarpo interno e endocarpo. 32. Detalhe do pirênio (mesocarpo interno e endocarpo) em diferenciação; notar as primeiras células já lignificadas (ponta de seta). 33. Região do septo. 34. Vista geral da semente; notar a grande semelhança com o óvulo. 35 . Detalhe da região calazal. ( $c a=$ calaza; $c s=$ cavidade seminal; en $=$ endocarpo $; \mathrm{fu}=$ funículo $; \mathrm{hp}=$ hipóstase $; \mathrm{me}=$ mesocarpo externo $; \mathrm{mi}=$ mesocarpo interno $; \mathrm{nu}=$ nucelo $; \mathrm{pe}=$ pericarpo $; \mathrm{sm}$ $=$ semente $)$. Barras $=400 \mu \mathrm{m}(29,34), 100 \mu \mathrm{m}(30,32), 50 \mu \mathrm{m}(31,33,35)$.

Figures 29-35. Fruit of Byrsonima intermedia in the end of cellular elongate stage. Longitudinal sections $(29,30,32,34,35)$. Transverse sections $(31,33) .29$. General aspect of pericarp. 30. Detail of pericarp (arrowhead = sclereid). 31. Detail of the inner pericarp region, detaching the structure of inner mesocarp and endocarp. 32. Detail of the pyrene (inner mesocarp and endocarp) in differentiation; note the first cells already lignificate (arrowhead). 33. Aspect of the septum. 34. General view of the seed; to note the great similarity with ovule. 35 . Detail of the chalazal region. $(\mathrm{ca}=$ chalaza; $\mathrm{cs}=$ seminal cavity; en $=$ endocarp; $\mathrm{fu}=$ funicle; $\mathrm{hp}=$ hipostasis; $\mathrm{me}=$ outer mesocarp; $\mathrm{mi}=$ inner mesocarp; $\mathrm{nu}=$ nucellus; pe $=$ pericarp; $\mathrm{sm}=$ seed $).$ Bars $=400 \mu \mathrm{m}$ $(29,34), 100 \mu \mathrm{m}(30,32), 50 \mu \mathrm{m}(31,33,35)$. 


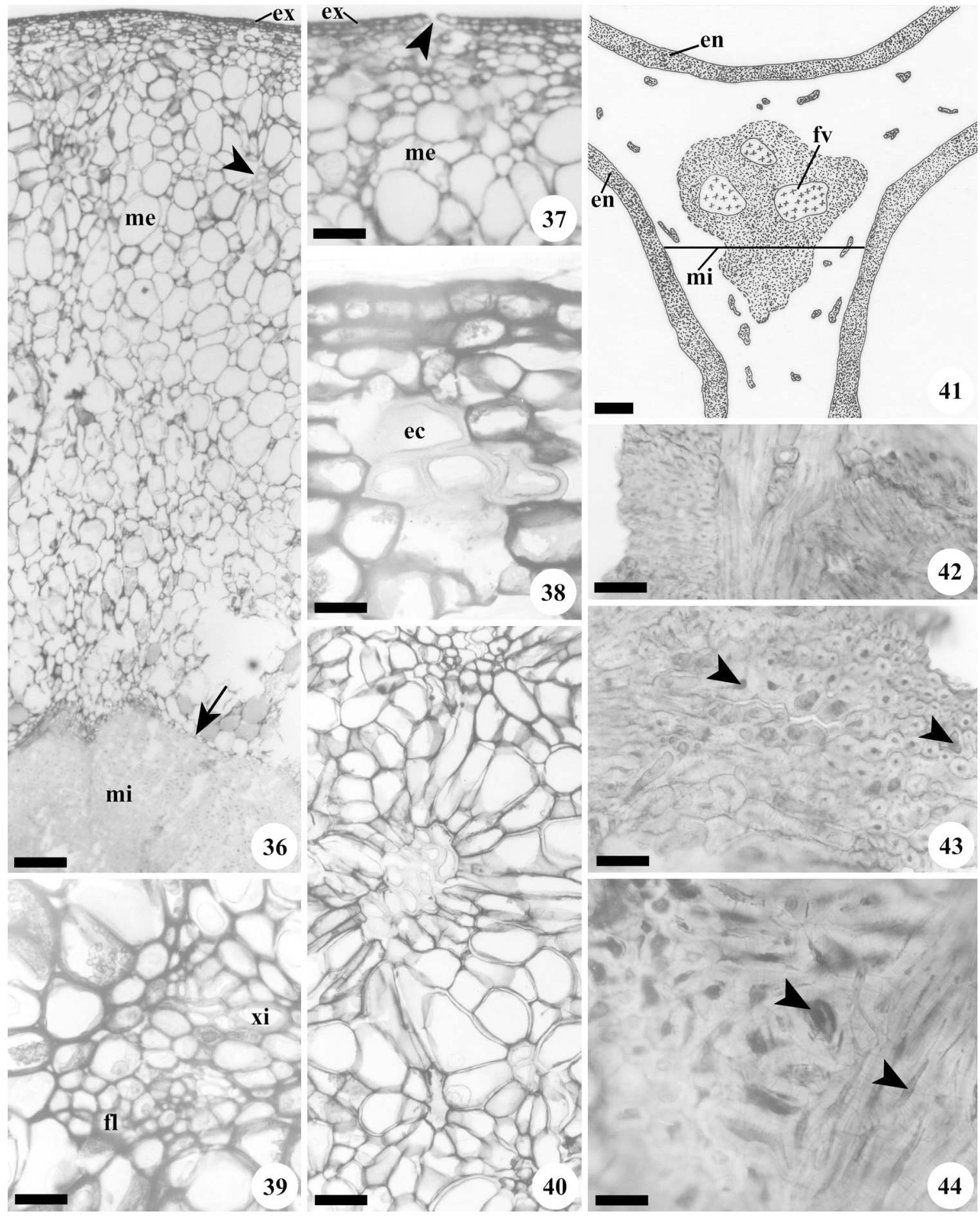

Figuras 36-44. Pericarpo maduro de Byrsonima intermedia. Secções transversais. 36. Aspecto geral do pericarpo; notar as células achatadas (seta) da interface do mesocarpo externo e interno (ponta de seta $=$ esclereíde). 37. Porção periférica do pericarpo, destacando o exocarpo com estômato (ponta de seta). 38. Detalhe do exocarpo e mesocarpo externo, evidenciando esclereídes e espaços intercelulares. 39. Detalhe do feixe vascular. 40. Aspecto do mesocarpo externo, exibindo o arranjo radial das células parenquimáticas junto às esclereídes. 41. Aspecto geral da região ventral; no mesocarpo interno as fibras possuem arranjos variáveis, sendo somente verticais no endocarpo (áreas pontilhadas: fibras verticais). 42. Detalhe do septo, evidenciando o arranjo das células mesocárpicas e endocárpicas. 43-44. Detalhe das células lignificadas do mesocarpo interno; notar o acúmulo de compostos fenólicos (ponta de seta). (ec = esclereíde; en = endocarpo; ex = exocarpo; $\mathrm{fl}=$ floema; $\mathrm{fv}=$ feixe ventral; $\mathrm{me}=$ mesocarpo externo; $\mathrm{mi}=$ mesocarpo interno; $\mathrm{xi}=$ xilema $)$. Barras $=200 \mu \mathrm{m}(36,41)$, $100 \mu \mathrm{m}(37,40), 25 \mu \mathrm{m}(38,39,44), 50 \mu \mathrm{m}(42,43)$. 

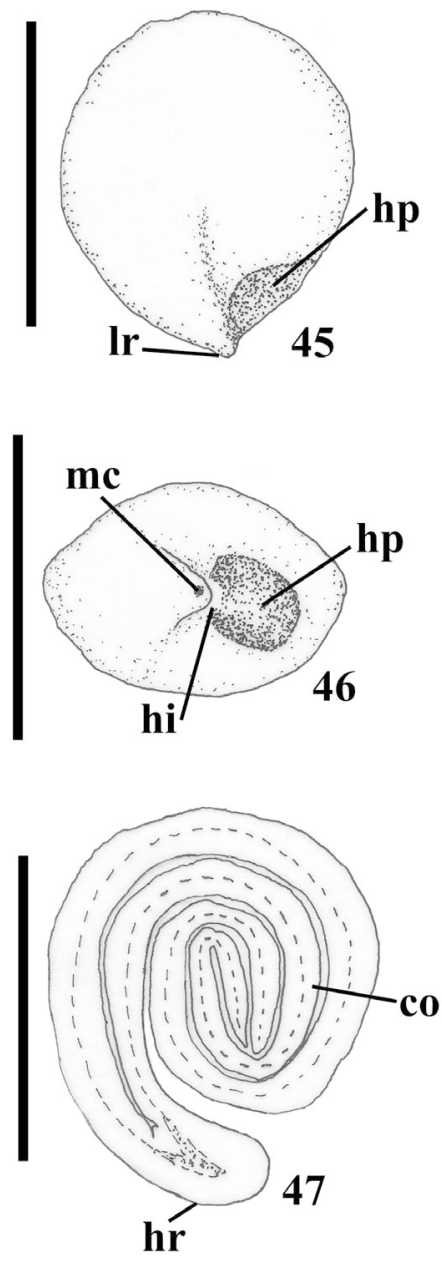

Figuras 45-47. Semente madura de Byrsonima intermedia. 45. Vista lateral, destacando o lobo radicular e a hipóstase. 46. Vista hilo-micropilar. 47. Embrião em secção longitudinal. (co = cotilédone; hi $=$ hilo; hp = hipóstase; $\mathrm{hr}=$ eixo hipocótilo-radicular; $1 \mathrm{r}=1$ lobo radicular; $\mathrm{mc}=$ micrópila). Barras $=3 \mathrm{~mm}$.

Figures 45-47. Mature seed of Byrsonima intermedia. 45. Lateral view, detaching the radicular lobe and hipostasis. 46. Hilum-micropylar view. 47. Embryo in longitudinal section. $($ co = cotyledon hi $=$ hilum; hp = hipostasis; $\mathrm{hr}=$ embryo axis; $\mathrm{lr}=$ radicular lobe $; \mathrm{mc}=$ micropyle $)$. Bars $=3 \mathrm{~mm}$. apresentavam a hipóstase, pode-se associar a ocorrência de hipóstase e outros caracteres ancestrais, como a formação de óvulos bitegumentados (em $73 \%$ das espécies avaliadas), crassinucelados (72\%), desenvolvimento nuclear de endosperma (74\%) e hábito arbóreo (64\%) em ambiente tropical (58\%). Todas estas características enquadram a família Malpighiaceae, especialmente o gênero Byrsonima, de modo que seria esperada a diferenciação da hipóstase. Ainda com relação a essa estrutura, não há consenso na literatura a respeito de considerá-la um caráter ancestral (Von Teichman \& Van Wyk 1991) ou derivado (Corner 1976).

Com relação à epístase, Corner (1976) e Werker (1997) consideraram sua ocorrência mais restrita que a hipóstase. Segundo os autores, a epístase pode ser verificada em sementes de Zingiberaceae, Nymphaeaceae e alguns membros de Myrtaceae. Registros de outros grupos têm sido encontrados, como para Bombacaceae (Marzinek \& Mourão 2003) e, neste trabalho, para Malpighiaceae.

Uma característica típica de sementes retidas em pericarpos lenhosos e indeiscentes é a transferência da função de proteção realizada pelos tegumentos, para o pericarpo (Boesewinkel \& Bouman 1984), com a conseqüente redução estrutural dos envoltórios seminais. Essa característica é verificada nos frutos drupóides, que apresentam os tegumentos reduzidos, sendo sua função de proteção transferida para o pirênio. Tal fenômeno foi tipicamente observado nos frutos de $B$. intermedia. Além de frutos drupóides, o processo também foi descrito para sementes formadas em sâmaras de diversas espécies, como por exemplo em Tipuana tipu (Benth.) O. Kuntze (Martins \& Oliveira 2001) e Pterocarpus violaceus Vog. (Nakamura \& Oliveira 2005). Tegumentos pouco diferenciados, segundo Boesewinkel \& Bouman (1984), ocorrem em famílias avançadas com frutos indeiscentes como por exemplo, os drupóides.

Segundo a classificação de Martin (1946), as sementes de $B$. intermedia possuem embrião dominante

Figures 36-44. Mature pericarp of Byrsonima intermedia. Transverse sections. 36. General aspect of pericarp; note the flattened cells (arrow) of the interface of outer and inner mesocarp (arrowhead $=$ sclereid). 37. Peripheral portion of pericarp, detaching exocarp with stoma (arrowhead). 38. Detail of exocarp and outer mesocarp, evidencing sclereids and intercellular spaces. 39. Detail of the vascular bundle. 40. Aspect of outer mesocarp, showing the radial arrangement of the parenchyma cells close to sclereids. 41. General aspect of the ventral region; in inner mesocarp the fibers possess changeable arrangements, being only vertical in endocarp (dotted areas: vertical fibers). 42. Detail of septum, evidencing the arrangement of the mesocarpic and endocarpic cells. 43-44. Detail of the lignified cells of the inner mesocarp; note the phenolic compounds (arrowhead). (ec = sclereid; en = endocarp; ex = exocarp; $\mathrm{fl}=$ phloem; $\mathrm{fv}=$ ventral bundle; $\mathrm{me}=$ outer mesocarp; $\mathrm{mi}=$ inner mesocarp; $\mathrm{xi}=\mathrm{xylem})$. Bars $=200 \mu \mathrm{m}(36,41), 100 \mu \mathrm{m}(37,40), 25 \mu \mathrm{m}(38,39,44), 50 \mu \mathrm{m}(42,43)$. 

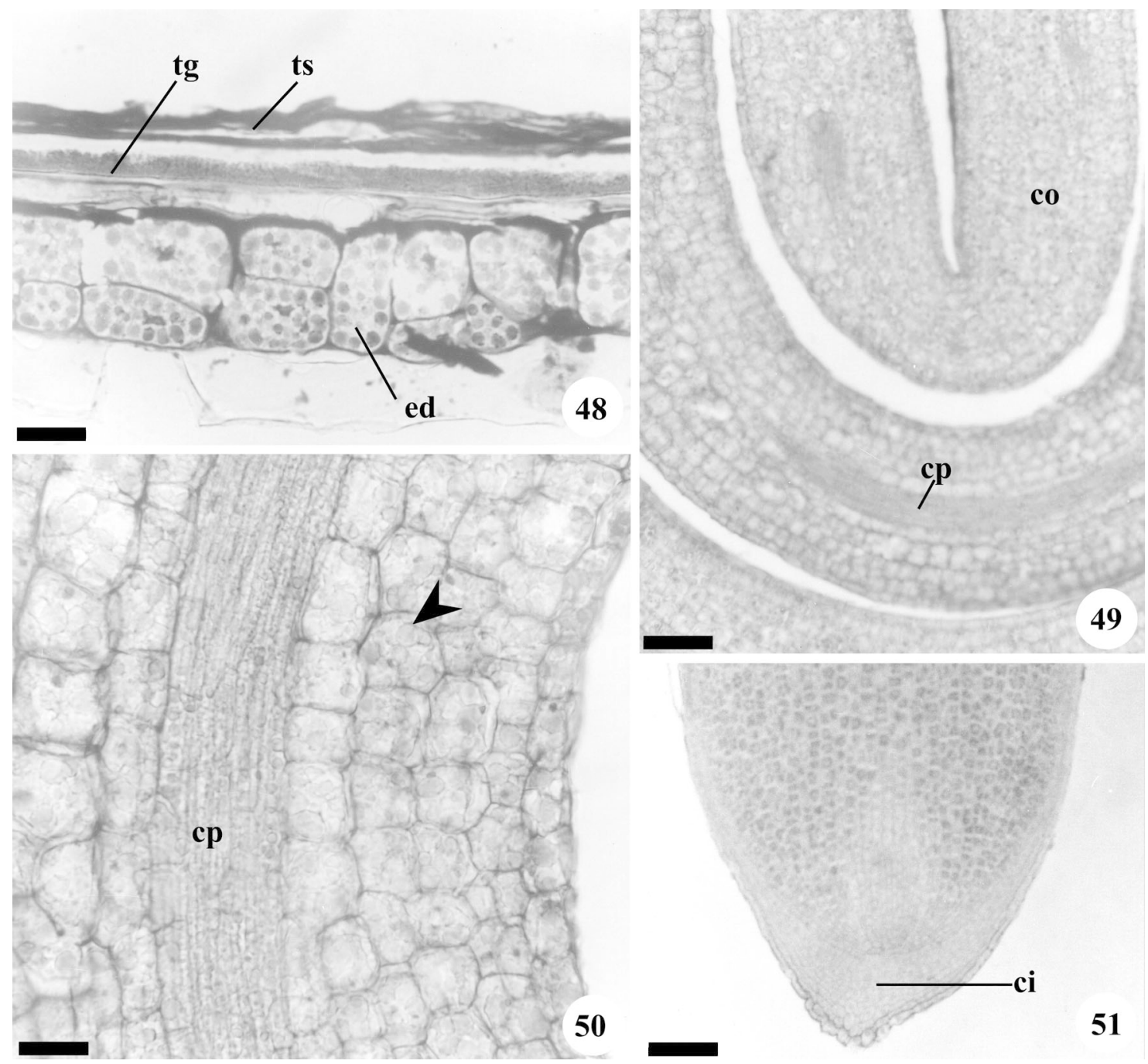

Figuras 48-51. Semente madura de Byrsonima intermedia. Secções longitudinais. 48. Detalhe dos tegumentos e endosperma; observar gotículas lipídicas no citoplasma das células endospérmicas. 49. Aspecto geral dos cotilédones. 50. Detalhe do cotilédone $($ ponta de seta $=$ gotícula lipídica). 51 . Radícula com primórdio de coifa. $(\mathrm{ci}=\mathrm{coifa} ; \mathrm{co}=\mathrm{cotilédone} ; \mathrm{cp}=\mathrm{cordão}$ procambial; ed = endosperma; $\operatorname{tg}=$ endotégmen; $\mathrm{ts}=$ exotesta). Barras $=25 \mu \mathrm{m}(48,50), 100 \mu \mathrm{m}(49,51)$.

Figures 48-51. Mature seed of Byrsonima intermedia. Longitudinal sections. 48. Detail of the integuments and endosperm; note the droplets of lipid on the cytoplasm of the endosperm cells. 49. General aspect of cotyledons. 50. Detail of the cotyledon (arrowhead = lipid drop). 51. Radicle with root cap primordium. ( $\mathrm{ci}=$ root cap primordium; co $=$ cotyledon; $\mathrm{cp}=$ procambial string; $\mathrm{ed}=$ endosperm; $\operatorname{tg}=$ endotegmen; $\mathrm{ts}=$ exotesta). Bars $=25 \mu \mathrm{m}(48,50), 100 \mu \mathrm{m}(49,51)$.

e axial, embora não se enquadrem nos tipos descritos pelo autor. De acordo com a proposta de Barroso et al. (1999), o embrião de $B$. intermedia é axial, porque ocupa a região central da semente, contínuo, já que não ocorre clara delimitação entre o eixo hipocótilo-radicular e os cotilédones, e do tipo circinado, visto que o embrião é cilíndrico e enrolado em espiral. Essa morfologia embrionária é descrita na referida literatura como característica do gênero Byrsonima.

Estudando Janusia guaranitica (Malpighiaceae), Lorenzo (1981) descreveu um único tegumento que se diferencia, com a epiderme formada por células grandes com alto conteúdo de compostos fenólicos. Em $B$. intermedia também existe uma camada de células com compostos fenólicos mas, diferentemente do que ocorre em J. guaranitica, os dois tegumentos se diferenciam. Corner (1976) registrou as sementes bitegumentadas como características das Malpighiaceae, fato corroborado pela espécie de Byrsonima estudada.

Nos frutos e sementes estudados, observa-se uma grande concentração de idioblastos contendo compostos fenólicos. Os compostos fenólicos são considerados um 
tipo de defesa química contra a herbivoria (Swain 1979). Essa grande concentração é importante, principalmente no cerrado, ambiente onde esta planta encontra-se adaptada e em que existe grande predação dos frutos e sementes por herbívoros.

Agradecimentos - À Fapesp, pelo auxílio financeiro (Proc. Biota-Fapesp 2000/12469-3) e pela bolsa de iniciação científica de L.S. Souto (Proc. 2002/03360-3).

\section{Referências bibliográficas}

ANDERSON, W.R. 1977. Byrsonimoideae, a new subfamily of the Malpighiaceae. Leandra 6-7:5-18.

ANDERSON, W.R. 1979. Floral conservatism in neotropical Malpighiaceae. Biotropica 11:219-223.

ANDERSON, W.R. 1981. Malpighiaceae. Botany of the Guiana Highland - Part XI. Memoirs of the New York Botanical Garden 32:21-305.

ANDERSON, W.R. 1990. The origin of the Malpighiaceae the evidence from morphology. Memoirs of the New York Botanical Garden 64:210-224.

BARROSO, G.M., PEIXOTO, A.L., ICHASO, C.L.F., COSTA, C.G., GUIMARÃES, E.F. \& LIMA, H.C. 1984. Sistemática de Angiospermas do Brasil. v.2. Imprensa Universitária da Universidade Federal de Viçosa, Viçosa.

BARROSO, G.M., MORIM, M.P., PEIXOTO, A.L. \& ICHASO, C.L.F. 1999. Frutos e sementes: morfologia aplicada à sistemática de dicotiledôneas. Editora UFV, Viçosa.

BOESEWINKEL, F.D. \& BOUMAN, F. 1984. The seed: structure. In Embryology of Angiosperms (B.M. Johri, ed.). Springer-Verlag, Berlin, p.567-610.

CORNER, E.J.H. 1976. The seeds of dicotyledons. University Press, Cambridge, $2 \mathrm{v}$.

DOP, P. \& GAUTIÉ, A. 1909. Manual de technique botanique. J. Lamane, Paris.

GERLACH, G. 1969. Botanische Mikrotehnik, eine einfuhrung. George Thieme, Stuttgart.

JENSEN, W.A. 1962. Botanical histochemistry: principles and pratice. W.H. Freeman, San Francisco.

JOHANSEN, D.A. 1940. Plant microtechnique. McGraw-Hill Book, New York.

JULIO, P.G.S. 2003. Morfologia e anatomia dos frutos e sementes de Styrax camporum Pohl. (Styracaceae), espécie de cerrado do estado de São Paulo. Dissertação de mestrado, Instituto de Biociências, Universidade Estadual Paulista, Botucatu.

KRAUS, J.E. \& ARDUIN, M. 1997. Manual básico de métodos em Morfologia Vegetal. EDUR, Seropédica.

LILLELAND, O. 1930. Growth study of the apricot fruit. Proceedings of the American Society of Horticultural Sciences 27:237-245.
LILLELAND, O. 1932. Growth study of the peach fruit. Proceedings of the American Society of Horticultural Sciences 29:8-12.

LILLELAND, O. 1933. Growth study of the plum fruit - I. The growth and changes in chemical composition of the climax plum. Proceedings of the American Society of Horticultural Sciences 30:203-208.

LORENZO, E. 1981. Sobre la inflorescência, morfologia floral y embriologia de Janusia guaranitica (Malpighiaceae). Kurtziana 14:101-124.

MARTIN, A.C. 1946. The comparative internal morphology of seeds. The American Midland Naturalist 36:513-660.

MARTINS, M.A.G. \& OLIVEIRA, D.M.T. 2001. Morfoanatomia e ontogênese do fruto e semente de Tipuana tipu (Benth.) O. Kuntze (Fabaceae: Faboideae). Revista Brasileira de Botânica 24:109-121.

MARZINEK, J. \& MOURÃO, K.S.M. 2003. Morphology and anatomy of the fruit and seed in development of Chorisia speciosa A. St.-Hil. - Bombacaceae. Revista Brasileira de Botânica 26:23-34.

MENDONÇA, R.C., FELFILI, J.M., WALTER, B.M.T., SILVA JÚNIOR, M.C., REZENDE, A.V., FILGUEIRAS, T.S. \& NOGUEIRA, P.E. 1998. Flora vascular do cerrado. In Cerrado: ambiente e flora (S.M. Sano \& S.P. Almeida, eds.). Embrapa - CPAC, Brasília, p.288-556.

NAKAMURA, A.T. 2003. Morfologia e anatomia dos frutos e sementes de três espécies de Erythroxylum P. Browne (Erythroxylaceae) de cerrado do estado de São Paulo. Dissertação de mestrado, Instituto de Biociências, Universidade Estadual Paulista, Botucatu.

NAKAMURA, A.T. \& OLIVEIRA, D.M.T. 2005. Morfoanatomia e ontogênese da sâmara de Pterocarpus violaceus Vogel (Fabaceae: Faboideae). Revista Brasileira de Botânica 28:375-387.

NITSCH, J.P. 1953. The physiology of fruit growth. Annual Review of Plant Physiology 4:199-236.

O'BRIEN, T.P., FEDER, N. \& MCCULLY, M.E. 1964. Polychromatic staining of plant cell walls by toluidine blue O. Protoplasma 59:368-373.

RIBEIRO, J.E.L.S., HOPKINS, M.J.G., VICENTINI, A., SOTHERS, C.A., COSTA, M.A.S., BRITO, J.M., SOUZA, M.A.D., MARTINS, L.H.P., LOHMANN, L.G., ASSUNÇÃO, P.A.C.L., PEREIRA, E.C., SILVA, C.F., MESQUITA, M.R. \& PROCÓPIO, L.C. 1999. Floresta da reserva Ducke: guia de identificação das plantas vasculares de uma floresta de terra-firme na Amazônia Central. Inpa, Manaus, p.505-511.

ROTH, I. 1977. Fruits of Angiosperms. Gebrüder Borntraeger, Berlin.

SASS, J.E. 1951. Botanical microtecnique. Iowa State University, Ames.

SINGH, B. 1964. Development and structure of Angiosperm seed - I. Bulletin of the National Botanic Gardens, India 89:1-115. 
SWAIN, T. 1979. Tanins and lignins. In Herbivores: their interaction with secondary plant metabolities (G.A. Rosenthal \& D.H. Janzen, eds.). Academic Press, New York, p.657-674.

TUKEY, H.B., YOUNG, J.O. 1939. Histological study of the developing fruit of the sour cherry. Botanical Gazette 100:723-749.
VON TEICHMAN, I. \& VAN WYK, A.E. 1991. Trends in the evolution of dicotyledonous seeds based on character associations, with special reference to pachychalazy and recalcitrance. Botanical Journal of the Linnean Society 105:211-237.

WERKER, E. 1997. Seed anatomy. Gebrüder Borntraeger, Berlin. 